Revista Complutense de Historia de América

ISSN: $1132-8312$

https://dx.doi.org/10.5209/rcha.75316

\title{
La región del Plata en los años del Trienio Liberal: proyectos políticos y trayectorias vitales
}

[en] The La Plata Region during the Liberal Triennium: Political Projects and the Life Trajectories

Ivana Frasquet ${ }^{1}$; Laura Martínez Renau ${ }^{2}$

Encauzado hacia la celebración del bicentenario del Trienio Liberal, el presente monográfico tiene como objeto profundizar en la coyuntura político-revolucionaria de los años veinte del siglo XIX haciendo énfasis en la región rioplatense. Ha sido ésta una década parcialmente olvidada por la historiografía especialista en la disolución de los imperios de las monarquías ibéricas. Por ello, son varias las razones que justifican un acercamiento detenido hacia este período de la historia iberoamericana; bastaría con repasar los trabajos publicados en los últimos años para reconocer el silencio existente en torno a la década de 1820, tanto para la mayoría de las historias nacionales iberoamericanas como para el caso español. Pero al interés que encierra en sí mismo el estudio de un período hasta ahora poco transitado para los historiadores, se suman otros motivos que vertebran esta propuesta.

Por un lado, el Trienio inaugura una nueva etapa para la monarquía española en la que se retomó el ideario liberal proclamado en Cádiz en la década anterior. A pesar de ello, 1820 no representa únicamente un punto de inflexión en territorio español pues el triunfo del liberalismo alentó también el inicio de una revolución en el país vecino, Portugal, y en extensión en su colonia atlántica más importante, Brasil. En este sentido, las monarquías ibéricas se vieron en la tesitura de transitar hacia un constitucionalismo que compartía fecha de inicio, pero también de conclusión, pues el año de 1823 pondrá fin a ambos proyectos liberales en la Península. Aún así, la década de 1820 no pudo suponer un regreso sin más al punto donde quedó derrotado el liberalismo en 1814, entre otras cosas porque la coyuntura europea había cambiado considerablemente. La Restauración de las monarquías absolutistas será un contexto mucho más hostil para el desarrollo de las propuestas constitucionalistas, sobre todo en la Península. En contrapartida, el eje revolucionario virará hacia Iberoamérica, protagonizando las independencias faltantes en el continente y el inicio de los nuevos Estados, republicanos o monárquicos. Tanto es así que la tensión entre la monarquía y la república es otro de los puntos nodales de la década que se pretende explorar en estos trabajos.

\footnotetext{
Universitat de València.

E-mail: Ivana.Frasquet@uv.es

2 Universitat de València.

E-mail: laura.Martinez-Renau@uv.es
} 
Por otro lado, es evidente que el fin del absolutismo en la península repercutió en parte del Cono Sur americano y en especial en la región del Plata. Cuando los liberales lusos requirieron la vuelta de la Corte de los Braganza a Lisboa, Brasil disputó la supremacía política del Reino con su antigua metrópoli, siendo la década de 1820 la que consolidó la independencia brasileña y la formación de su primera monarquía constitucional. Por su parte, la Banda Oriental estaba, desde 1817, militarmente ocupada por las tropas portuguesas y en 1821 formalizó su incorporación a la monarquía lusa. Esta anexión del antiguo territorio hispánico al Reino Unido acentuó el desacuerdo entre los representantes brasileños y portugueses en las Cortes de Lisboa y generó no poca confusión en una región que vivió toda la década bajo dominio luso hasta que consiguió su independencia en 1828. Por su parte, las Provincias Unidas del Río de la Plata y Chile, que habían proclamado ya su independencia, se verán inmersas durante este período en un complejo proceso de construcción de sus Estados-nación que verá florecer proyectos de intenciones federalistas de distinta intensidad. Son éstas, las existentes entre el federalismo y el centralismo, otras tensiones que transitarán a lo largo de la década en la región. Igualmente, las disputas entre la monarquía y la república generarán no pocos debates y discusiones en los congresos que se van a reunir a lo largo de esta década en todo el territorio, como ya hemos indicado.

Por todo ello, en este monográfico pretendemos abordar las propuestas políticas que, siendo triunfantes o no, pudieron condicionar el resultado de la configuración de los nuevos Estados americanos en esta región sudamericana. En este sentido, el enfoque no es ajeno a los debates historiográficos que en las últimas décadas han situado el período de las independencias iberoamericanas en el centro de la discusión. Si bien, por un lado, la llamada Atlantic History ha puesto el énfasis en resaltar las conexiones que a ambos lados del océano mantuvieron los territorios americanos y Europa, por otro, la asunción de los procesos revolucionarios - la "Era de las Revoluciones"- como elemento vertebrador en la disolución de las monarquías ibéricas, agudizó la percepción de la disgregación de los imperios como punto axial de todo el proceso. Ello produjo un interesante debate historiográfico en torno a las continuidades y rupturas que las independencias generaron y dio lugar a buenos trabajos que se esforzaban por demostrar una u otra posición.

Es cierto que, recientemente, los investigadores que se han dedicado a este período y, concretamente, a los procesos de independencias iberoamericanos, han matizado estas posiciones, encontrando profundos lazos de unión en un proceso aparentemente centrífugo que, si bien balcanizó el espacio iberoamericano en multitud de nuevas repúblicas, también generó conexiones que se basaron en la experiencia común, en pensarse políticamente sin la monarquía, en enfrentar una nueva realidad como pudo ser la guerra, etc. Todo ello sin desmerecer la génesis de un nuevo lenguaje político constitucional y liberal que puso en práctica unas también nuevas formas de configuración de los espacios institucionales y de gobierno de las monarquías y de las repúblicas. Esto, al mismo tiempo, generó una cultura política con significados y prácticas distintas y entre las que se incluyeron las modernas concepciones sobre la soberanía y la nación o la representación, entre otras. La comprensión compleja de esos procesos políticos debe abordarse desde la diversidad de las experiencias iberoamericanas y desde la heterogeneidad social latente en ellas que provocó experiencias políticas plurales, adaptadas al marco colonial existente pero no exentas de profundos cambios compatibles con la modernidad. Es a partir de esta 
complejidad que pretendemos abordar los años 20 en esta región como un momento de cambio y consolidación de las experiencias iniciadas en la década anterior. En general estos años han sido soslayados en la historiografía, interpretados como momentos de transición entre la independencia y la construcción de la república, obviando que fue precisamente entonces cuando se gestaron las transformaciones y los proyectos políticos que cristalizarían en las nuevas repúblicas. A veces se olvida que el origen de éstas estuvo, precisamente, en la década de los años 20, todavía en un contexto de guerra en algunos territorios o incluso vinculados a la monarquía española, cuya presencia se mantuvo en muchos lugares estratégicos hasta finales de la década.

Así, a través de cinco estudios de casos, el monográfico expone diferentes elementos de la cultura política gestada durante la década de 1820 , planes y proyectos políticos impulsados, bien desde la península, bien desde el Cono Sur en los que se muestra la importancia de esta coyuntura histórica para el futuro de los Estadosnación en la región.

En el caso del trabajo de Marcela Ternavasio, se explora el experimento reformista desplegado en Buenos Aires entre 1821 y 1824, conocido en la historiografía argentina como la "feliz experiencia". Desde la perspectiva de la historia política e intelectual, la autora recorre los lenguajes políticos sobre los que se asentaron las reformas y la proyección de la cuestión constitucional como foco de análisis, así como los vínculos entre sociedad y poder político. A partir de los casos de estudio de Bernardino Rivadavia y Manuel José García, como principales artífices de las reformas de cuño liberal e ilustrado que se aplicaron en el Estado de Buenos Aires, se recuperan las distintas conexiones o variaciones que los principios revolucionarios, constitucionales y liberales pudieron adoptar durante esos años. Rivadavia fue designado ministro de Gobierno y García de Hacienda en 1821, y desde esos encumbrados cargos emprendieron un plan de transformación política, económica, social y cultural. De este modo, el trabajo aborda ambas trayectorias con el objeto de iluminar las diferentes miradas y proyecciones que presentan respecto del lugar que debía ocupar el nuevo orden independiente del Río de la Plata en el tablero internacional y, especialmente, en el contexto de disputas entre las monarquías ibéricas en el corredor luso-hispano-criollo del Atlántico Sur.

De este modo, la "cuestión oriental" estuvo en el centro de tales disputas y abrió diferentes perspectivas acerca de cómo resolver un conflicto que atravesó con diversas variantes y contendientes el período de la Restauración, el Trienio liberal, la independencia de Brasil y el ensayo constituyente del Río de la Plata. Esa centralidad se observa también en el caso del texto de Ivana Frasquet, que aborda las trayectorias vitales de dos personajes como Miguel de Lastarria y Francisco Magariños, ambos muy vinculados a la región platense y, en especial, a Montevideo. El cambio sustancial en las directrices del gobierno de Fernando VII a partir de 1820, obligará a los actores políticos a posicionarse y a reconfigurar sus identidades y sus horizontes de expectativas en el marco de una coyuntura constitucional sustancialmente diferente a la de la década anterior. Las soluciones propuestas a la crisis que se abrió con "la cuestión americana" durante el Trienio Liberal, abarcaron proyectos políticos distintos, aunque como se demuestra en este estudio, las posturas iniciales de fidelidad a la monarquía pudieran ser comunes. En ambos casos de estudio se pueden observar las transferencias culturales y las readaptaciones y/o modificaciones de unas conductas políticas que respondieron a la difícil y cambiante coyuntura de la década. 
Estas experiencias de sociabilidad, de redes de comunicación y de construcción de cultura política también pueden observarse en el trabajo de Paula Botafogo, a través de la vivencia del exilio del periodista brasileño João Soares Lisboa en el Cono Sur. La región fronteriza entre el imperio de Brasil y los territorios hispanoamericanos, actuó como espacio indeterminado para estos exiliados que, desde el orden liberal, entendieron su experiencia hispanoamericana como una oportunidad para rearticular el juego político e influir en el gobierno del imperio de Brasil. Como indica la autora, el exilio es analizado como tránsito cultural, con la construcción de fronteras y redes imaginarias, así como, adquisición de experiencias y miradas sobre el "otro". En este sentido, desde la reedición del Correio do Rio de Janeiro, João Soares Lisboa, negoció letras de cambio y armas con "rebeldes de Montevideo", organizado cenas y reuniones para la discusión de la política de la Corte de Río de Janeiro y envió cartas a sus aliados por barcos comerciales y soldados portugueses. Así, el exilio es visto no como un destierro político o una condena, sino como una oportunidad de integrar la memoria histórica sobre las trayectorias de estos actores en estos decisivos años.

Y es en esta centralidad de la región del Plata en la que se enmarcan los debates institucionales y los juegos políticos de los recién creados parlamentos al calor de los procesos revolucionarios. La ocupación del territorio oriental por parte de las tropas brasileñas, hizo que la guerra se extendiera a la provincia Cisplatina, incorporada a la monarquía de los Braganza desde 1821. En Montevideo, tal y como estudia Laura Martínez, se convocó un congreso extraordinario para discutir sobre el futuro del territorio. La Cisplatina quedó dividida en dos facciones que se disputaron la gobernabilidad: de un lado, los fieles al rey João VI, representados por la División de Voluntarios Reales en la capital; del otro, los brasileños en la campaña, partidarios de incorporar el territorio al Imperio del Brasil. Los proyectos políticos de ambos bandos cristalizaron en la disputa mantenida entre el rey João VI y el príncipe regente don Pedro, hasta que este último declaró la independencia de Brasil en 1822. Esta circunstancia conllevó la convocatoria de una asamblea general constituyente y legislativa del imperio brasileño, cuyo encargo sería elaborar la primera constitución política del país. En esos debates sobre la formación del Estado y la nación brasileños se centra el trabajo conjunto de Rafael Fanni y Joao Paulo G. Pimenta. Partiendo del concepto de "experiencia", que recorre de una u otra manera todo el dossier, ambos autores ejemplifican cómo las discusiones en esta asamblea y en la opinión pública a través de la prensa, fueron atravesadas por el ejemplo hispanoamericano que incidió en los debates de los constituyentes brasileños.

La finalidad del monográfico, por tanto, es presentar cómo la década de 1820 es fundamental para comprender el proceso de construcción de las nuevas repúblicas americanas (o monarquía, en el caso brasileño) en la región del Plata a partir de las propuestas políticas que circularon durante todo el período, bien fuera dentro o al margen de los espacios institucionales destinados para ello. Con ello queremos también incluir la participación de actores cuyas trayectorias vitales transitaron durante esta década y a través de las cuales se puede reconstruir un espacio político cuyos marcos de definición se amplían más allá del encaje tradicional. Lo político abarcó mucho más que lo institucional, y a pesar de que en la mayoría de los casos fue en los espacios tradicionales destinados para ello (los parlamentos, los cabildos, etc.) donde se generó la mayor parte de los proyectos de la época, también al margen de ellos pudo construirse parte de esa cultura política que se consolidaría con el liberalismo republicano o monárquico de las décadas posteriores. 